\title{
A Study of Core-Plus Students Attending Michigan State University
}

\author{
Richard O. Hill and Thomas H. Parker
}

1. INTRODUCTION. One important measure of the effectiveness of a high school mathematics program is the success students have in subsequent university mathematics courses. Yet this measure is seldom considered in studies of high school curricula. This article describes a study that we undertook to quantify this measure for one particular curriculum.

Readers of this MONTHLY may be aware of the general context leading to the need for such evaluative studies. Over the past two decades there has been a growing awareness of the inadequacy of the mathematical skills of American high school graduates. That was the assessment of the 1983 report A Nation at Risk [14] and confirmed by many subsequent studies. A recent National Assessment of Educational Progress (NAEP) Report [3] concluded that only 17 percent of U.S. twelfth graders were "proficient" at mathematics. ${ }^{1}$ International comparisons also indicate a relatively low level of mathematics achievement by U.S. high school students. The Third International Mathematics and Science Study (TIMSS) assessed the "Mathematics Literacy" of end-ofsecondary students in twenty-two countries and found that U.S. students outperformed only two countries, Cyprus and South Africa [18]. Related studies suggest that the mathematics courses taken by American high school students are often at a lower level than those taken by their international peers and that U.S. high schools are offering a wide assortment of courses that lack the focus and coherence found in many foreign curricula [19]. This situation has been of particular concern on college and university campuses, where large numbers of entering students require remedial courses to bring their mathematical knowledge and skills up to what is required for a wide variety of college courses.

One effort to improve school mathematics began in 1989 with the publication of Curriculum and Evaluation Standards for School Mathematics (generally known as "The NCTM Standards") by the National Council of Teachers of Mathematics [5]. The National Science Foundation (NSF) subsequently funded the development and implementation of thirteen elementary, middle, and high school mathematics curricula based on these Standards, programs variously referred to as "reform," "Standardsbased," or "NSF-sponsored" by their publishers and others. Many of these programs have been controversial. In particular, there has been concern that the NSF-sponsored curricula moved from pilot testing to large-scale implementation without sufficient independent evaluations of their efficacy in preparing students for college mathematics and science courses.

Although studies of the effectiveness of these curricula have yielded promising conclusions (see, for example, the collection of such evaluations in [17]), most have been conducted by persons associated with their writing or implementation. A recent National Research Council (NRC) report, On Evaluating Curricular Effectiveness [8], also expresses concerns about the methodological adequacy of these studies. This NRC

\footnotetext{
${ }^{1}$ The notion of "proficient" used in this statistic is identified by the National Assessment Governing Board as the minimal level that all students (included those not headed for college) should reach.
} 
report calls for a renewed focus on evaluations that incorporate multiple methodologies, use unbiased evaluative criteria, and are conducted by independent researchers. The report calls specifically for more longitudinal research on the effectiveness of the Standards-based curricula, including studies of how well high school reform curricula prepare students for success in college.

College-bound students are not an elite group. Approximately 70 percent of the graduates of American high schools enroll at two- or four-year colleges within two years of graduation [21]. There is evidence that mathematics preparation is pivotal in this transition: an extensive study by Adelman [1] examined the influence of many factors on college graduation rates and found that the most significant factor was the amount and quality of mathematics taken in high school.

Unfortunately, there appears to be a "disconnect" between the mathematics expectations that students encounter in K-12 education and those that they encounter in college. This is among the conclusions of the NRC report [8, p. 161] and of Stanford University's Bridge Project, which concludes that "Students, parents, and K12 educators are not receiving clear messages about the skills that high school students need to enter and succeed in college" [11], [22]. In these reports the need for research into the effectiveness of high school mathematics curricula for college preparation is coupled with a call for mathematicians, as well as mathematics educators, to participate in these studies $[\mathbf{8}$, p. 5] and to articulate specifics about the mathematics needed for success in their courses.

Our study addresses this need by evaluating the effectiveness of one "reform" curriculum: the Core-Plus Mathematics Project (described in the next section). To that end, we analyzed the college mathematics records of students arriving at Michigan State University (MSU) from four high schools that implemented the Core-Plus Mathematics program between 1996 and 1999.

Here is a quick summary of the study results. As the implementation progressed, from 1996 to 1999, Core-Plus students placed into, and enrolled in, increasingly lower level courses; this downward trend is statistically robust $(p<.0005)$. The percentages of students who (eventually) passed a technical calculus course show a statistically significant $(p<.005)$ decline averaging 27 percent a year; this trend is accompanied by an obvious and statistically significant increase in percentages of students who placed into low-level and remedial algebra courses. The grades the Core-Plus students earned in their university mathematics courses are also below average, except for a small group of top students. ACT scores suggest the existence but not the severity of these trends.

Details of the results are given in sections 5 and 6. Section 8 contains suggestions for constructing similar large-scale studies of students' transitions from high school to college mathematics.

2. THE CORE-PLUS PROGRAM AND MSU. The Core-Plus program, which is commonly abbreviated CP or CPMP, is a series of four high school textbooks entitled Contemporary Mathematics in Context: A Unified Approach [4]. This program was developed with NSF funding beginning in the year 1992 by the Core-Plus Mathematics Project based at Western Michigan University. The Core-Plus website describes the program as follows:

Contemporary Mathematics in Context is a four-year curriculum that replaces the traditional Algebra-Geometry-Advanced Algebra/Trigonometry-Precalculus sequence. Each course features interwoven strands of algebra and functions, statistics and probability, geometry and trigonometry, and discrete mathematics. The 
first three courses in the series provide a common core of broadly useful mathematics for all students. They were developed to prepare students for success in college, in careers, and in daily life in contemporary society. Course 4 continues the preparation of students for college mathematics.

The Core-Plus curriculum features mathematical modeling, extensive use of graphing calculators, and a minimal amount of algebra until the fourth year. ${ }^{2}$ The Core-Plus program was first pilot tested in the 1993-94 school year. According to figures cited in an NSF grant proposal by the Core-Plus Mathematics Project, the program is now used by over 200,000 students in more than five hundred schools.

Michigan State University is well-suited for a study of this kind. It is a large $(43,000$ students) public university whose students come from a wide variety of mathematics curricula. Because of its size and popularity, the Core-Plus high schools in this study sent many students to MSU (an average of twenty-one per year per school). Moreover, in large part because MSU has a mathematics requirement for graduation, roughly 90 percent of MSU students take mathematics courses during their freshman year. As a result, MSU records provide a large and varied set of data to analyze.

3. LITERATURE REVIEW. There is a body of evidence finding that high school CPMP students, when compared with peers enrolled in traditional mathematics classes, have better problem-solving skills but perform less well on tests of algebra skills (the distinction between "problem-solving" and "algebra" skills is defined by the particular testing instruments created by the investigators). For example, Huntley et al. [10] concluded that CPMP students performed better than traditional-curriculum students on problems involving formulating algebraic models and interpreting the results of calculations [10, p. 345], but the results were reversed for problems that focused on symbolic manipulations [10, p. 348]. Schoen and Hirsh report similar results in [15] and [16]. For example, they write [15, p. 341]:

Results [of various exams] consistently show that CPMP students are stronger than comparison students in more traditional curricula in conceptual understanding, interpretation of algebraic representations and calculations, and problem solving in realistic contexts, but somewhat weaker in out of context, paper-andpencil symbolic manipulation.

Despite this evidence at the high school level, very little work has been done to examine how Core-Plus students fare in subsequent college mathematics courses. We could find only four studies that addressed this issue. All four involve Michigan high schools and colleges.

- A conference presentation by Lewis, Lazarovici, and Smith [12] reported on a study of seven Core-Plus students who placed into precalculus or calculus at MSU. All but one of those students found Calculus 1 "a major struggle." The authors noted, however, that some of these students may have had only three years of Core-Plus and that Core-Plus exposes students to statistics and other topics that are not part of a traditional college-preparatory sequence, so calculus may not be the appropriate college course for Core-Plus students.

- As part of her Ph.D. dissertation, R. Walker [23] followed six students as they moved from high school to college (MSU and the University of Michigan, Ann Arbor). All

\footnotetext{
${ }^{2}$ The fourth year of the program was not implemented until the 1998-1999 school year and the Core-Plus Course 3 was later modified to include more algebra.
} 
six had taken the complete Core-Plus curriculum and been recommended for the study by a high school teacher. Three of these students did well in their college mathematics courses and three had difficulties. The study notes that some students expressed concerns about their lack of algebra skills [23, p. 238], and two took an algebra course at a nearby college in preparation for their university studies.

Two other studies examined the graduates of two high schools in an affluent Detroit suburb. One of these schools was a pilot site for the Core-Plus program, and the other did not use Core-Plus material.

- Bachelis and Milgram [13] analyzed data from a survey of students from these two schools. On all of the measures they examined (ACT Math and SAT Math scores, level of college courses taken, and grades in those courses) the students from the Core-Plus school performed significantly less well than the students from the nonCore-Plus school. However, those conclusions are based on a nonrandom sample of student-reported data (volunteered responses from 50 percent of the graduates at the Core-Plus school and 25 percent of those at the non-Core-Plus school).

- Coxford (one of the Principal Investigators of the original NSF grant awarded to the Core-Plus project) obtained data on the mathematics courses taken and grades received by the students from these same two high schools who subsequently enrolled at the University of Michigan at Ann Arbor. His data are reported by H. Schoen and C. Hirsch, who conclude that the "preliminary evidence suggests that students who experienced the pilot Core-Plus curriculum were at least as well prepared for calculus (AP or college level) as students in a more traditional curriculum" $[\mathbf{1 5}, \mathrm{p}$. 340].

Again there is a caveat: this was a population of top students, many of whom had taken AP Calculus in addition to Core-Plus courses. In fact, according to U.S. News \& World Report's American's Best Colleges 2003 (pages 82-84), 69 percent of University of Michigan freshmen (verses 26 percent of MSU freshmen) come from the top 10 percent of their high school class. Furthermore, four of the five University of Michigan courses in the Coxford study correspond to Tier 1 courses at MSU, and incoming freshmen in three of these five courses necessarily had AP Calculus credit.

Altogether, despite the positive assessments of CPMP at the high school level, the literature contains only limited studies of the efficacy of CPMP in preparing students for college-level mathematics, and those studies are inconclusive.

4. METHODOLOGY. This study is a spin-off of a much larger study [9] examining achievement in university mathematics courses by students arriving at Michigan State University in the years 1996-1999. We invited forty-five high schools from central Michigan to participate in that large study; each sent at least ten students a year to MSU. From MSU records we obtained admissions and course-grade data for the students who came to MSU from these schools during the period of the study. Thirty-four of the schools also provided information on the senior-year high school mathematics courses taken by their students. The result was a data set on roughly 3200 students from a variety of high school mathematics curricula.

Six of the forty-five high schools used CPMP as their high school mathematics curriculum. The present study focuses exclusively on the students from those six schools. Five of these declined to provide student high school records. Consequently, for the study of these six schools, we used a study design requiring only the data that were available to us from MSU. 
Study design. We began with a list of all students who graduated from the six CorePlus high schools in our sample in the years 1996-99 and enrolled at MSU. We obtained, from MSU records, those students' ACT scores, scores on the Mathematics Placement exam, and a list of the mathematics courses they took at MSU and the grades they received. More recent data were not available when we began the study, but we later obtained data for the 1994, 1995, and 2000 students from several of these schools. However, two of the six high schools supplemented the Core-Plus program by incorporating material from other curricula. We separated the data from those two schools and analyzed them separately (see the end of section 6).

That left four schools that were implementing a system of offering only Core-Plus mathematics (and possibly AP Calculus for students who had completed the Core-Plus program). These four schools represented a variety of communities: one is in the center of a medium-size city, one in an affluent suburb, and two in a developing rural area. All four implemented the Core-Plus curriculum in such a way that very few of their 1996 graduates had taken Core-Plus courses, but a significant and increasing number of their 1998 and 1999 students had taken at least three of the four Core-Plus courses and no other mathematics course except possibly AP calculus. The students from these four schools constitute our Core-Plus group (the "CP group").

The goal of our statistical analysis was to look for trends over time in the college mathematics performance of the graduates of the CP-group schools. Did the students who graduated later (the groups who had the most exposure to the Core-Plus program) perform significantly better than those who graduated from the same high schools earlier (the groups with less Core-Plus exposure)? To answer that question, we separated the $\mathrm{CP}$ group into subgroups according to the year of graduation. For each subgroup, we examined the data from the students' first university mathematics course. We looked for trends over time for several measures of success: level of the course taken, grades in those courses, and success rates for moving on to higher mathematics courses.

Of course, trends over time may be attributable to changes in MSU programs, courses, or policies, or to changes in the population of students enrolling at MSU. To see if that was the case, we did a parallel analysis on data for students from the thirty-four high schools in our database that did not use the Core-Plus program as their primary mathematics program (the "Control group"). These high schools used a wide variety of mathematics programs and textbooks. We did not attempt to subdivide or classify these but simply took this large group as representative of the mix of programs being used in Michigan high schools. This control group is essentially a "non-Core-Plus" group. ${ }^{3}$

These analyses were feasible and sensible because both groups were reasonably large ( $n=353$ and $n=2961$, respectively), because we had complete records of the MSU mathematics courses taken by all students in both groups, and because we also had ACT English scores to use as an independent assessment of the abilities of these groups of students. The results are presented in section 5 .

Freshman mathematics courses at MSU. For this study we have grouped the freshman-level MSU mathematics courses into five tiers. The following discussion describes those tiers and gives background information about the MSU mathematics program.

\footnotetext{
${ }^{3}$ However, as part of the mix, it includes a small percentage ( 3.1 percent) of students who had taken at least one Core-Plus course. These students were retained in the control group to maintain its representative character.
} 
Nearly seven thousand freshmen enter MSU each fall. It is crucial that these students are placed into mathematics courses that are at a level appropriate for them. That is done through a Mathematics Placement Exam designed by the MSU Mathematics Department. The exam is evaluated each year (and revised when appropriate) using several different standard statistical checks of the correlation between Placement Exam scores and the grades students achieve in the courses where they were placed by the exam. These internal Mathematics Department studies show that the Placement Exam directs students into courses appropriate for them.

Here is a brief description of the five tiers, including the Placement Exam score (out of a maximum score of 28) needed to place into the courses in that tier. (Syllabi, textbooks used, and sample final exams are available at the website www .math.msu . edu.) These are all one-semester courses.

- Tier 1: Math 132 (technical calculus) or a higher level course. Admission into these courses requires a score of 19 on the Placement Exam, an ACT math score of 28, a SAT math score of 640, or a passing score on the AP calculus exam.

- Tier 2: Five different courses. Specifically, (a) business/biological science calculus, (b) trigonometry, (c) elementary education math, (d) a statistics course, and (e) a recently created "liberal arts math" course. Admission into these courses requires a Placement Exam score of 15 (except the trigonometry course, which requires credit for college algebra).

- Tier 3: A precalculus course (Math 116) designed to prepare students for technical calculus, although about half of the students enroll for other purposes. Admission into this course requires a Placement Exam score of 12.

- Tier 4: A traditional "college algebra" course for three credits, and a five-credit course on finite math and algebra. A Placement Exam score of 10 or higher places students into this tier.

- Tier 5: Intermediate Algebra. This three-credit remedial course does not earn credit towards graduation, but does count in a student's GPA.

As a requirement for graduation, all MSU students must pass, or place out of, one mathematics course beyond the level of college algebra. Many large universities have similar graduation requirements. This requirement can be met either by scoring at least 19 on the (proctored) Placement Exam or by receiving a passing grade in any mathematics or statistics course except for Intermediate Algebra or College Algebra. Intermediate Algebra and College Algebra cover material commonly found in high school mathematics curricula; nevertheless, during the years of this study about 40 percent of incoming freshmen placed into these two courses.

Nearly all of the students in the courses listed intend to major in something other than mathematics. Consequently, representatives of the mathematics department periodically consult with other departments about the content of these courses. Feedback from these meetings is used to ensure that these courses are meeting the needs of the other departments.

For this study students were assigned to the tier of the first mathematics course they took at MSU. Students who took no MSU mathematics course were placed either into the tier of the highest-level course for which they had received transfer or AP credit, or into Tier 1 if they received 19 or better on the proctored Placement Exam. The remaining students, who had neither mathematics courses nor credit (and therefore had not yet fulfilled the MSU mathematics graduation requirement), were placed into a separate group labeled "None." 
5. RESULTS. We analyzed the data from the Core-Plus and the Control groups, looking for trends over time in three measures of performance in university mathematics: the level of the first mathematics courses that students took at MSU, the grades they attained in those courses, and the percentage of students who eventually passed a Tier 1 course at MSU. We focused on the students' first mathematics courses and grades because those most strongly reflect the level of the students' mathematics preparation in high school. The "eventually passed Tier 1" data is a measure of the rate at which students in these groups are taking the mathematics courses needed for technical majors such as engineering, physical science, and economics. This section presents the results of a statistical analysis of these three measures.

Courses taken. At the beginning of their freshman year, the students themselves choose their mathematics courses from the options available to them as determined by their Placement Exam, ACT or SAT scores, AP Exam scores, or transfer credit. (Students can revise their choice during the first two weeks of classes.) Table 1 shows data on the distributions of the first mathematics courses taken at MSU. The first four columns give the distributions for students in the Control group who graduated in the years 1996-99; the next four columns give the corresponding distributions for CorePlus students. Each column lists the percentages of students who took courses in Tiers 1-5 and the percentage who took no mathematics course. The last four columns of Table 1 give the ratio $\mathrm{CP} / \mathrm{Control}$ of percentages for each year and each tier. That ratio is a convenient way of comparing the two groups and has the additional advantage that any year-to-year variations common to both groups cancel in the ratio. Because the Core-Plus high schools implemented the program in different years, what is relevant are trends in the course distribution over the years of the study.

Before looking at trends we note that in the initial year of the study the CorePlus group was not statistically different from the Control group. Specifically, a $\chi^{2}$ comparison of the first and fifth columns of Table 1 shows no statistically significant difference ( $p=0.57$ on five degrees of freedom); similarly there was no significant difference between the 1996 groups in ACT English or ACT Math scores ( $p=0.78$ and $p=0.28$, respectively). Thus the 1996 Core-Plus group, while not obtained through a randomized study design, has a profile compatible with what one would expect from a random sample of the 1996 control population.

Table 1. First courses at MSU—distribution by tiers.

\begin{tabular}{|l|ccc|ccccc|ccc|c|}
\hline & \multicolumn{3}{|c}{$\begin{array}{c}\text { Control (Percent) } \\
(n=2961)\end{array}$} & \multicolumn{3}{c|}{$\begin{array}{c}\text { CP(Percent) } \\
(n=353)\end{array}$} \\
\hline Year & 1996 & 1997 & 1998 & 1999 & 1996 & 1997 & 1998 & 1999 & 1996 & 1997 & 1998 & 1999 \\
$n$ & 682 & 780 & 768 & 731 & 75 & 89 & 107 & 82 & & & & \\
\hline Tier 1 & 18 & 20 & 24 & 21 & 15 & 13 & 9 & 6 & 0.80 & 0.67 & 0.39 & 0.29 \\
Tier 2 & 13 & 12 & 16 & 18 & 12 & 10 & 5 & 9 & 0.94 & 0.77 & 0.29 & 0.48 \\
Tier 3 & 18 & 15 & 14 & 12 & 20 & 13 & 13 & 10 & 1.08 & 0.91 & 0.92 & 0.80 \\
Tier 4 & 29 & 27 & 26 & 27 & 36 & 27 & 39 & 33 & 1.26 & 1.00 & 1.50 & 1.20 \\
Tier 5 & 19 & 22 & 15 & 19 & 17 & 33 & 28 & 38 & 0.89 & 1.45 & 1.81 & 1.95 \\
None & 2 & 4 & 4 & 2 & 0 & 4 & 6 & 5 & 0 & 1.13 & 1.35 & 2.10 \\
\hline
\end{tabular}

Several trends are obvious in Table 1. In Tiers 1 and 2 there seems to be no significant year-to-year change in the Control group, but there is a clear downward trend in the Core-Plus group. The ratios show that in 1998 and 1999 students from CorePlus high schools were taking Tiers 1 and 2 courses at only about one-third the rate 
of their Control group peers. In Tier 5 there is also little year-to-year change in the Control group but an upward trend in the Core-Plus group. The ratios rise to the point where Core-Plus students are taking this remedial course at roughly twice the rate of the Control group students.

To determine whether these changes are statistically significant, the data in Table 1 were analyzed using a logistic regression model (for technical details about this model, see [2, chap. 5] or [20, sec. 8.4]). The null hypothesis is that the data are drawn from a distribution that is constant in time. The model detects linear trends in the log-odds ratios of the corresponding entries of the column vectors of Table 1.

Here is a technical description of the model. Let $X_{i j}$ be one of the $6 \times 4$ matrices that give the enrollments for the $\mathrm{CP}$ or the Control group (the actual enrollments, rather than the percentages as in Table 1). Let $X_{j}$ be the $j$ th column, and let $n_{j}$ be the sum of the entries of $X_{j}$. We assume the columns are stochastically independent and that each column has a multinomial distribution, $Y_{j} \sim \mathcal{M}_{6}\left(P_{j}=\left(p_{1 j}, \ldots p_{6 j}\right), n_{j}\right)$. Here, the $p_{i j}$ are probabilities and $p_{1 j}+\cdots+p_{6 j}=1$. The expected value of the $j$ th column is a vector $m_{j}=E\left(X_{j}\right)=n_{j} P_{j}$. We incorporate these vectors into the $6 \times 4$ matrix $m=\left[m_{1} \cdots m_{4}\right]$. Let $\mu$ be the $6 \times 4$ matrix obtained by taking the natural logarithm $\log m$ of $m$ component-wise.

The model approximates $\mu$ as a linear combination

$$
\mu=\log m \approx \beta_{0} \bar{I}+\sum_{i=1}^{5} \rho_{i} R_{i}+\sum_{j=1}^{3} \gamma_{j} C_{j}+\delta D,
$$

where $\bar{I}$ is the $6 \times 4$ matrix of all $1 \mathrm{~s}, R_{i}$ is the $6 \times 4$ matrix whose $i$ th row is all $1 \mathrm{~s}$ and all other entries are $0, C_{j}$ is the $6 \times 4$ matrix whose $j$ th column is all $1 \mathrm{~s}$ and all other entries are 0 , and $D$ is the outer product $[0 \cdots 5]^{T}[1 \cdots 4]$ (which is a $6 \times 4$ matrix that represents the interaction between the rows and columns). The data determine estimates of the parameters $\beta_{0}, \rho_{i}, \gamma_{j}$, and $\delta$. The number of real interest is the "logodds-ratio" $\delta$, which is a measure of the drift away from no change in the entries.

This model provides answers to three distinct questions: Does this model fit the data reasonably? Are the trends in the two sets of data significant? And how do the two sets of data compare? The results, obtained using the $\mathrm{glm}$ function in the statistical package $\mathrm{S}+$, are as follows:

- For the Core-Plus data, the residual deviance (the $\chi^{2}$-value on fourteen degrees of freedom) is 12.99 , indicating that the model fits these data very well. The estimate for $\delta$ is 0.134 with a $z$-value of 3.46. Thus the downward drift in the Core-Plus table is statistically significant $(p<.0005){ }^{4}$

- For the Control group data, the residual deviance $\left(\chi^{2}\right.$ on fourteen degrees of freedom) is 38.9 , indicating that the model, while not fitting the data as well as in the previous case, is reasonable given that $n$, the number of students, is large. For these data the estimate for $\delta$ is -.028 with a $z$-value of -2.48 . Thus there is a slight upward drift in the Control distribution that is statistically significant $(p=.013)$.

- Finally, the $z$-statistic for the comparison between the estimated drifts for the CorePlus and the Control data is statistically significant $(p<.0001)$. Specifically, let $\hat{\delta}_{C P}$

\footnotetext{
${ }^{4}$ As mentioned in section 4, we started with six Core-Plus schools and separated out two of them. At one of these schools, supplementation was done within Core-Plus courses and their non-Core-Plus courses were mainly for students not bound for college. If that school's data are included in Table 1, the residual deviance is 12.4 , the estimate for $\delta$ is 0.097 with a $z$-value of 2.66, and the downward drift in the revised Core-Plus table is still statistically significant $(p<0.008)$.
} 
(respectively, $\hat{\delta}_{C}$ ) denote the estimated drift for the $\mathrm{CP}$ (respectively, Control) data, and let $\sigma_{C P}$ (respectively, $\sigma_{C}$ ) be the corresponding standard deviations. Then the $z$-statistic is

$$
\frac{\hat{\delta}_{C P}-\hat{\delta}_{C}}{\sqrt{\sigma_{C P}^{2}+\sigma_{C}^{2}}} \approx \frac{.1335+.0276}{\sqrt{.039^{2}+.0111^{2}}} \approx 3.97
$$

corresponding to a $p$-value of .00007 .

Grades. We now turn from the courses students took to the grades they earned in those courses. As mentioned earlier, MSU mathematics department studies show that the Placement Exam is generally effective at placing students into courses appropriate for them. On the other hand, it may be possible that the trends seen in Table 1 arise from unidentified shortcomings in the placement process rather than shortcomings in the preparation of Core-Plus students.

To determine the validity of the placement process, we examined the grades that students attained in their first course at MSU. The first two columns of Table 2 list the average grades in the first MSU courses taken by students in our sample who arrived at MSU in Fall 1998 and 1999 (we restrict attention to those years because some high schools did not adopt Core-Plus until Fall 1994). The last two columns give, for each tier, the $z$-statistic and $p$-value of the $\chi^{2}$-test comparing the grade averages.

Table 2. Average grades in the first MSU courses taken by 1998-1999 students.

\begin{tabular}{|c|c|c|r|r|}
\hline & Control & CP & $z$ & $p$ \\
\hline Tier 1 & $2.79(n=301)$ & $3.25(n=10)$ & -2.05 & .04 \\
Tier 2 & $2.86(n=244)$ & $2.21(n=12)$ & 1.51 & 0.13 \\
Tier 3 & $2.36(n=195)$ & $2.08(n=20)$ & 1.17 & 0.24 \\
Tier 4 & $2.29(n=391)$ & $1.92(n=67)$ & 2.39 & .02 \\
Tier 5 & $2.31(n=251)$ & $1.92(n=60)$ & 2.11 & .04 \\
\hline
\end{tabular}

For Tiers 2-5 Table 2 shows that the Core-Plus students had lower averages than their Control group peers. In Tiers 4 and 5, these differences are statistically significant at the .05 level. Thus the data on grades provide no indication that the Core-Plus students were taking courses beneath their abilities. In fact, the Core-Plus students, on average, earned slightly worse grades in Tier $2-5$ courses than the control group students.

The first row of Table 2 is quite different: the Core-Plus group definitely obtained better grades in Tier 1 courses. That is perhaps not surprising, because the Tier 1 grades for the CP group in Table 2 are obtained from an increasingly selective group of students, changing from the top 15 percent in 1996 to the top 6 percent in 1999 (cf. Table 1). A second possible factor is the effect of AP Calculus, which is often taken by top mathematics students. Nevertheless, Table 2 shows that there was an elite group of ten students (out of 169) who did extraordinarily well in some Tier 1 course at MSU. Interpreting that fact would require knowledge of which high school courses these ten students took.

It is illuminating to look at the grade distributions for the 1998-99 students who took Tier 3-5 courses (that includes 87 percent of the Core-Plus students). For those students, the mean grade was 2.31 for the Control group and 1.94 for the Core-Plus group, a difference that is statistically significant $(p<.002)$. The grade distributions, 
shown in Figure 1, make clear how that difference arises: a markedly lower percentage of students in the Core-Plus group received grades of 3.5 and 4 and a correspondingly higher percentage received grades of 1.5 or less.

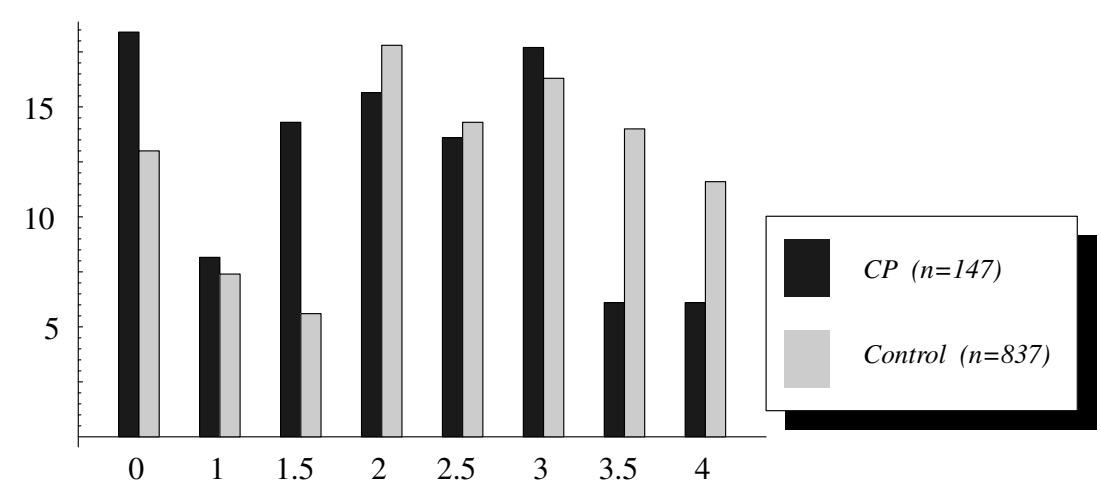

Figure 1. Grades of 98-99 students in Tier 3-5 courses (percentage receiving each grade).

Passing calculus eventually. As a third measure for judging the preparation of CorePlus students for university-level mathematics, we looked at the percentages of students who eventually passed a Tier 1 course. At MSU, as at most colleges and universities, the first course in the Tier 1 technical calculus sequence is required for a broad spectrum of engineering and physical science majors. It is a standard first-semester calculus course; essentially the same course is taught at a wide range of universities and in high school AP calculus classes. It requires a fluent working knowledge of algebra, geometry, and trigonometry - the subjects of high school mathematics. The percentage of students who pass Tier 1 calculus therefore provides a possible measure of the depth of high school mathematics preparation.

Our counts of those who "passed Tier 1 sometime" include students who received AP or transfer credit for calculus and those who passed a Tier 1 course as sophomores, juniors, or seniors at MSU, but they do not include those who took the Tier 2 "business calculus" course. For comparison, during the years of this study about 25 percent of the freshmen who entered MSU eventually passed Tier 1 calculus courses.

Figure 2 shows how the percentages of students who "passed Tier 1 sometime" changed over the four years of the study. The percentages for the Core-Plus group clearly decline. The best-fitting (maximum likelihood) line to the log-odds shows that the Core-Plus percentages fall at a rate of about 27 percent per year, a significant

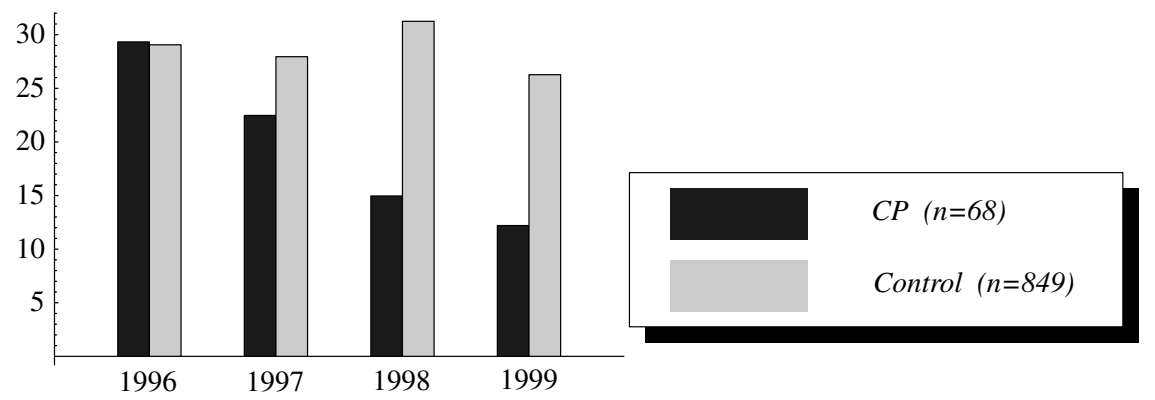

Figure 2. Percentage of students who passed Tier 1 courses sometime. 
decline. (Here the $z$-value is -2.84 , corresponding to $p<.005$. The $\chi^{2}$-statistic on five degrees of freedom is 7.07, which indicates that the model fits the data well.) This chart presents a compelling case that a larger-scale study is merited.

6. OTHER ASPECTS OF THE DATA. This section presents data from several individual high schools. These were included in the composite data presented earlier, but looking at schools individually brings out several interesting phenomena not clearly visible in the previous analysis. In particular, we uncover evidence that ACT scores need to be treated with care when used to evaluate high school mathematics programs.

Transition in one district. Two of the Core-Plus schools, which we denote by CP4 and CP5, are in the same district (in fact, they began as a single high school and moved to separate buildings during the years of our study). For these two schools we were able to obtain seven years of data, giving a large sample $(n=254)$ from a single district. These schools implemented Core-Plus Course 1 in the 1994-5 school year and subsequently added one course each year. Thus students who graduated in the years 1994-1997 had not used Core-Plus materials, whereas some of the class of 1998, about half of the class of 1999, and most of the class of 2000 had taken Core-Plus courses. In the summer of 1999 this district's Board of Education reinstated a "traditional" track in mathematics as an option. As a result, the class of 2000 included about thirty students who had taken a special traditional precalculus class in their senior year.

Table 3. CP4-5: Average ACT and MSU Math Placement Exam Scores.

\begin{tabular}{|l|c|c|c|}
\hline High School graduation year & $1994-1997$ & $1998-2000$ & $p$-value \\
\hline ACT English & 23.3 & 23.1 & 0.64 \\
ACT Math & 23.8 & 22.8 & .06 \\
Placement & 12.6 & 11.5 & 0.10 \\
\hline
\end{tabular}

Table 3 shows the average ACT and MSU Math Placement Exam scores of the 94-97 group and the 98-00 group; the last column shows the $p$-values of the $\chi^{2}$-test comparing the groups. The very slight drop in ACT English scores is not significant, and the drops in ACT Mathematics and Placement Exam scores are only marginally significant. Thus the exam score data provide no firm statistical basis for predicting that the two groups would fare differently in their MSU mathematics courses.

Table 4. CP4-5: Distribution of first math courses taken at MSU, percentage in each tier.

\begin{tabular}{|l|rrrr|rrr|}
\hline $\begin{array}{l}\text { High School grad. year } \\
\text { number of students }\end{array}$ & $\begin{array}{c}1994 \\
17\end{array}$ & $\begin{array}{c}1995 \\
30\end{array}$ & $\begin{array}{c}1996 \\
33\end{array}$ & $\begin{array}{c}1997 \\
42\end{array}$ & $\begin{array}{c}1998 \\
41\end{array}$ & $\begin{array}{c}1999 \\
41\end{array}$ & $\begin{array}{c}2000 \\
50\end{array}$ \\
\hline Tier 1 & 24 & 23 & 18 & 26 & 10 & 7 & 10 \\
Tiers 2 \& 3 & 41 & 40 & 42 & 36 & 27 & 24 & 32 \\
Tiers 4 \& 5 & 35 & 33 & 39 & 33 & 63 & 68 & 54 \\
None & 0 & 3 & 0 & 5 & 0 & 0 & 4 \\
Passed Tier 1 sometime & 35 & 43 & 36 & 45 & 12 & 12 & 20 \\
\hline
\end{tabular}

The actual course data, given in Table 4, show a noticeable change in the distribution of the first mathematics courses taken at MSU by students from CP4 and CP5. There are obvious drops in the percentages of students who placed into the Tier 1 courses and who eventually passed Tier 1 courses, and an obvious increase in the percent- 
ages placing into remedial and low-level algebra (Tiers 4 and 5). These differences are statistically significant: the $\chi^{2}$-statistic for a test of the null hypothesis of equal proportions among the five categories in Table 6 was 38.4 on four degrees of freedom, with corresponding $p$-value $9 \times 10^{-8}$. (This large $\chi^{2}$-value is primarily due to the relatively small frequencies in the Tier 1 and "Passed Tier 1 sometime" categories and the large frequencies in the Tier 4 and 5 category in the 1998-2000 data.)

Many studies of high school mathematics have used ACT or SAT scores as measures of students' preparation for college on the assumption that those scores are well correlated to success in college mathematics courses. The data from CP4-5 suggest that study designs based on that assumption may fail to detect significant deficiencies in students' preparation for college-level mathematics-neither ACT scores nor Placement Exam scores predict the dramatic differences evident in the course data of Table 4.

A much-studied high school. One of the Core-Plus schools in our study, which we denote by $\mathrm{CP} 2$, was the subject of two of the studies mentioned in our literature review. Table 5 shows the distribution of mathematics courses taken by CP2 students who came to MSU over a six-year period. These distributions change between 1996 and 1997; there is again a decrease in the percentages of students who took Tier 1-3 courses and those who passed Tier 1 eventually, and a corresponding increase in the percentages for Tiers 4 and 5.

Table 5. CP2: Distribution of first math courses taken at MSU, percentage in each tier.

\begin{tabular}{|l|rrrrrr|}
\hline High School grad. year & 1994 & 1995 & 1996 & 1997 & 1998 & 1999 \\
number of students & 25 & 39 & 26 & 34 & 40 & 21 \\
\hline Tier 1 & 16 & 10 & 12 & 3 & 3 & 5 \\
Tiers 2 \& 3 & 32 & 15 & 27 & 9 & 10 & 5 \\
Tiers 4 \& 5 & 52 & 67 & 62 & 82 & 78 & 76 \\
None & 0 & 8 & 0 & 6 & 10 & 14 \\
Passed Tier 1 sometime & 20 & 15 & 19 & 6 & 5 & 5 \\
\hline
\end{tabular}

In both Tables 4 and 5 the level of courses taken declines abruptly between two consecutive years. The change occurs in different years, but in both cases it coincides with the first graduating class of Core-Plus students (the Core-Plus curriculum was begun with freshman at CP2 in 1993, a year earlier than at CP4 and CP5).

The patterns of ACT and MSU Math Placement scores, shown in Table 6, are also similar to those in Table 3. The increase in ACT English scores shown in Table 6 reflects a state and national trend. The ACT Math and MSU Placement Exam scores both decrease, but those declines again underestimate the downward trend seen in Table 5.

Table 6. CP2: Average scores on ACT and MSU Math Placement Exams.

\begin{tabular}{|l|llllll|}
\hline High School grad. year & 1994 & 1995 & 1996 & 1997 & 1998 & 1999 \\
\hline ACT English & 21.5 & 23.1 & 22.8 & 23.6 & 23.7 & 25.3 \\
ACT Math & 23.6 & 22.5 & 21.7 & 20.7 & 20.5 & 22.4 \\
Placement Exam & 13.7 & 11.2 & 12.3 & 10.0 & 10.6 & 10.7 \\
\hline
\end{tabular}


Schools supplementing Core-Plus. Four of the six schools in our Core-Plus group chose to adopt Core-Plus as their sole mathematics curriculum and to eliminate their previous curriculum, and two of them had completed this process by 1998-99. That purity seems to be rare: at least one study of the Core-Plus program has noted that "Most Core-Plus high schools maintain two different mathematics programs, CorePlus and a more traditional one" [12]. Among such schools there is no consistency in the options available: some have an alternative track, some offer various algebra and precalculus courses specifically aimed at preparing students for college mathematics, and some incorporate additional algebra and precalculus material directly into their Core-Plus courses.

As mentioned earlier, two high schools in our sample fit this "Supplemented CorePlus" profile. The information on their students was therefore not included in the data examined in section 5 (except for footnote 12). Both schools are relatively small, and the data on the MSU courses taken by their students is remarkably inconsistent (see Table 7). It is perhaps notable that the clear declines seen in the data from the four CP schools are not evident here. However, this data set is simply insufficient to draw any conclusions.

Table 7. Distribution (by percent) of first math courses for the "Supplemented Core-Plus" schools $(n=103)$.

\begin{tabular}{|l|cccc|}
\hline High School grad. year & 1996 & 1997 & 1998 & 1999 \\
\hline Tier 1 & 19 & 38 & 43 & 15 \\
Tiers 2 \& 3 & 31 & 10 & 25 & 22 \\
Tiers 4 \& 5 & 50 & 52 & 32 & 63 \\
Passed Tier 1 sometime & 27 & 43 & 54 & 19 \\
\hline
\end{tabular}

7. SUMMARY AND LIMITATIONS OF THE STUDY. In summary, our data show a clear decline in the level of Michigan State University mathematics courses taken by Core-Plus graduates. The existence of that decline is statistically significant at any reasonable level. The decline in course level is accompanied by a decline in average grades for all but the very top students, as well as a decline in the percentages of those who eventually passed a technical calculus course. These trends occur in data that include students from a variety of communities. The data from individual high schools show that the timing of these declines corresponds precisely to the implementation of the Core-Plus program.

Shortcomings of the methodology. This was not a large-scale randomized study. It involved a total of 353 students from four high schools implementing the Core-Plus program, and a group of 2961 students from other high schools used to control for variations in the measurement instruments (ACT scores, university grades, and placement exams). The data produced statistically reliable conclusions, but one would like to see the results replicated with a larger number of high schools and students moving to a variety of colleges and universities.

One important confounding variable is the fact that all four Core-Plus schools were in the initial years of implementing the curriculum. Schools and teachers face wellknown difficulties as they adopt a new curriculum, and it may be that the transition was especially problematic at these particular schools. Mitigating that effect is the fact that these schools provided teacher preparation and were committed to the implementation and, by the last year of the study, had had several years experience with the Core-Plus curriculum. 
In addition, this study involves only students at Michigan State University. While this population is reasonably representative of college students, it does not constitute a random sample of all Core-Plus students. In particular, it does not include students who enrolled at community colleges, who enrolled at elite universities, or who did not go to college. Consequently, this study can say nothing about Core-Plus outcomes for these populations of students.

The lack of information from the Core-Plus high schools made it impossible to ascertain precisely which students had completed the Core-Plus program and which had also taken non-Core-Plus mathematics courses such as AP calculus. We minimized that problem by restricting attention to schools with significantly increasing numbers of students taking Core-Plus courses and looking for trends over time. Nevertheless, the graduates of those schools still include, even in the last year studied, some students who took non-Core-Plus mathematics courses. A more refined study would distinguish those students.

There are also issues involving timing. The Core-Plus program is usually implemented by starting with Course 1 for ninth grade students and adding the subsequent courses one year at a time. In principle that creates a sudden shift, with one year's graduates having taken no Core-Plus courses and the following year's graduates having taken three or four Core-Plus courses. In our sample of four high schools, the year of the shift varied from school to school, and the shift occurred a year later for the "advanced" students (those who began high school mathematics in Grade 8). For two of the schools, there was an intermediate class in which roughly half the students began Core-Plus in Grade 9. Our analysis deals with this in two ways: by analyzing individual schools and by looking for log-linear trends in the composite data.

It is possible that observed trends are reflections of changing demographics in the population of the schools studied or in the ability levels of the students who chose to come to MSU. We looked for such treads by the standard method of examining ACT English scores. Those scores (see Tables 3 and 6) are consistent with the hypothesis that there were no substantial changes in the general academic level of the students in the Core-Plus group over the years studied.

Another timing issue concerns the Core-Plus program itself. The program and the manner of its implementation have been evolving. Core-Plus Course 4 was not implemented until the last year of this study, some schools that began implementing CorePlus as their only curriculum later incorporated additional material in various ways, and there is now a second edition of the Core-Plus texts. We did not examine any details of the implementations, such as teacher training. These are complicated issues that were impossible to sort out with the data we had. We also did not examine high school curricula that mix Core-Plus courses with more standard courses.

Finally, there is the problem of causal inference. While this study reports compelling trends in the data from the schools implementing Core-Plus, and while those trends are not present in the Control group, there is no guarantee that the trends are due to the Core-Plus program. All of the results of this paper must be read with that caveat in mind.

8. IMPLICATIONS FOR STUDIES EVALUATING NEW CURRICULA. The methodology and results of this study raise a number of issues relevant for future studies of curricula. We describe those issues in this brief section. The observations made here have implications for the design of studies of high school programs.

Curriculum evaluations may show that a program achieves the goals it was designed to achieve yet miss consequences that show up later. Program design goals necessarily involve choices about which mathematical topics bear emphasis, and they may include 
more subjective aims such as a positive attitude toward mathematics or success with certain types of problems within specific learning environments. Success in these goals does not necessarily mean that the students are prepared for subsequent mathematics and science courses.

Our study provides evidence for the suggestions in the NRC report On Evaluating Curriculum Effectiveness [8] that evaluations of new curricula should include followup studies at the next level of curriculum. Those follow-up studies should be done by independent researchers. This would produce a comprehensive literature that evaluates curricula on both the internal goals set by the curriculum designers and the external requirements that students face at the next level of their education.

That said, we have several recommendations that may help in designing reliable studies of how well high school programs prepare students for college mathematics. First, educational studies face an abundance of intertwined variables. It is important to choose methodologies that minimize the number of independent variables. Our study suggests such a methodology.

- Studies that compare school populations before and after whole-school implementation of a new program avoid many of the issues associated with extraneous variables.

This methodology minimizes variables associated with a mix of high school courses. The schools in our study began with an entirely non-Core-Plus curriculum and moved, over the years studied, steadily toward one that offered Core-Plus as students' only mathematics option (except for AP Calculus). Our statistical analysis looked for trends over time in those students' college mathematics achievements. This does not require knowledge of each student's high school courses and does not hinge on complete implementations of the new curriculum. It also avoids many confounding issues that would appear in studies of mixed-curricula schools such as the precise content of courses, how students selected courses, and what kind of "tracking" occurred.

This methodology also minimizes demographic variables. Our analysis compares students who had no exposure to the Core-Plus program with Core-Plus students who attended the same school a few years later. These two groups lived in the same community, attended the same high school, and often were taught by the very same teachers.

We also have two cautionary notes about specific types of data.

- ACT exam scores should not be relied upon by themselves to draw conclusions about the effectiveness of high school curricula. Most students take ACT exams during their junior year of high school, and the exams themselves involve material below junior level. Our results indicate that, at least in some circumstances, ACT math scores fail to reflect fully significant changes in student mathematics learning.

- Evaluations of high school curricula should be careful to treat AP Calculus students as a distinct group. AP Calculus is a highly structured curriculum designed to mimic a college calculus course. Studies have shown that AP calculus students do well in subsequent mathematics courses irrespective of their earlier high school curriculum [6], [7].

From a statistical viewpoint, one would ideally want randomized experiments to disentangle the effects of the curriculum from other potential explanations. As just discussed, our method of analysis goes a long way toward eliminating all variables except those directly associated with the implementation of the Core-Plus program, such as teacher training immediately before or during implementation, and associated 
changes in students' elementary and middle school mathematics preparation. Our work suggests that such large-scale studies assessing outcomes from high school programs can be done using university data.

9. CONCLUSION. The effectiveness of Core-Plus and the other new NSF-funded high school curricula programs is a significant issue for college mathematics faculty. High schools across the U.S. are adopting these programs in the hope of improving their students' understanding of mathematics. Increasing numbers of students are arriving on campus having learned mathematics using these programs.

One would hope that any new mathematics program would produce students who are at least as prepared for college mathematics as those coming out of the previous program. We undertook the present study to examine whether Core-Plus does that.

While the attribution of causality is impossible in this study, the results are compelling. Except for some top students, graduates of Core-Plus mathematics are struggling in college mathematics at Michigan State University. The evidence shows that they were less well prepared than either graduates in the Control group (who came from a broad mix of curricula) or graduates of their own high schools before the implementation of Core-Plus mathematics.

Despite the limitations of our study, these results raise serious issues about the effectiveness of CPMP in preparing students to take college mathematics courses at MSU. Our study did not attempt to pinpoint the reasons for CPMP students' difficulties. Those difficulties might be a result of inadequate enactments of the first edition of CPMP or of incompatibilities between the learning outcomes of CPMP and particular features of MSU mathematics courses (perhaps involving facility with algebra, as suggested by several of the studies cited in our literature review). Hence there is a serious need for a careful study of the new edition. We are initiating other studies that may help to localize such effects, and we hope that our present effort spurs other researchers, including college mathematics faculty, to examine the broad issues of how the adoption of reform curricula by high schools affects college mathematics learning.

ACKNOWLEDGMENTS. We are grateful to James Stapleton, who carried out much of the statistical analysis in this article and supplied invaluable advice. We also thank Marshall Hestenes for helping gather data from MSU records, and Gail Burrill, Joan Ferrini-Mundy, William H. Schmidt, and Jon R. Star for helpful comments.

\section{REFERENCES}

1. C. Adelman, Answers in the Tool Box: Academic Intensity, Attendance Patterns, and Bachelor's Degree Attainment, U.S. Department of Education, Washington, D.C., 1999.

2. A. Agresti, Categorical Data Analysis, Wiley-Interscience, New York, 1990.

3. J. S. Braswell, A. Lutkus, W. Grigg, S. Santapau, B. Tay-Lim, and M. Johnson, The Nation's Report Card: Mathematics 2000, U.S. Department of Education, Office of Educational Research and Improvement, National Center for Education Statistics, Washington, D.C., 2001.

4. A. F. Coxford, J. T. Fey, C. R. Hirsch, H. L. Schoen, G. Burrill, and A. E. Watkins (with M. J. Messenger and B. Ritsema), Contemporary Mathematics in Context: A Unified Approach (Courses 1-4). Glencoe/McGraw-Hill, Columbus, OH, 1997.

5. Curriculum and Evaluation Standards for School Mathematics, National Council of Teachers of Mathematics, Reston, VA, 1989.

6. E. M. Dickey, A comparison of advanced placement and college students on a calculus achievement test, Journal for Research in Math. Educ. 17 (1986) 140-144.

7. B. G. Dodd, S. J. Fitzpatrick, R. J. De Ayala, and J. A. Jennings, An Investigation of the Validity of AP Grades of 3 and a Comparison of AP and Non-AP Student Groups, College Board, 2002; available at www.collegeboard.com/repository/researchreport20029v2_18667.pdf 
8. On Evaluating Curricular Effectiveness: Judging the Quality of K-12 Mathematics Evaluations, National Research Council, Academic Press, Washington, D.C., 2004.

9. R. O. Hill, On the transition in mathematics from high school to Michigan State University (2006, preprint).

10. A. H. Huntley, C. L. Rasmussen, R. S. Villarubi, J. Sangtong, and J. T. Fey, Effects of standards-based mathematics education: A study of the Core-Plus Mathematics Project algebra and functions strand, Journal for Research in Math. Educ. 31 (2000) 328-361.

11. M. W. Kirst, The High School/College Disconnect, Educational Leadership 62 (2004) 51-55.

12. G. Lewis, V. Lazarovici, and J. Smith, Meeting the demands of calculus and college life: The mathematical experiences of graduates of some reform-based high school programs, paper presented at the Annual Meeting of the American Educational Research Associril 2001, Seattle, WA, April 2001.

13. R. J. Milgram, Outcomes analysis for Core Plus students at Andover High School: One year later (2001, preprint); based on data collected by G. Bachelis.

14. A Nation at Risk: The Imperative for Educational Reform, National Commission on Excellence in Education, U.S. Government Printing Office, Washington, D.C., 1983.

15. H. Schoen and C. Hirsch, The Core-Plus Mathematics Project: Perspectives and student achievement, in Standards-Oriented School Mathematics Curricula: What Does the Research Say About Student Outcomes?, S. L. Senk and D. R. Thompson, eds., Lawrence Earlbaum Associates, Hillsdale, NJ, 2003.

16. - Responding to calls for change in high school mathematics: Implications for collegiate and student achievement, this MONTHLY 110 (2003) 109-123.

17. S. L. Senk and D. R. Thompson, Standards-Based School Mathematics Curricula. What Are They? What Do Students Learn?, Lawrence Earlbaum Associates, Mahwah, NJ, 2003.

18. S. Takahira, P. Gonzales, M. Frase, and L. H. Salganik, Pursuing Excellence: A Study of U.S. TwelfthGrade Mathematics and Science Achievement in International Context, U.S. Department of Education, National Center for Education Statistics, Washington D.C., 1998.

19. W. H. Schmidt, Too little too late: American high schools in an international context, in Brookings Papers on Education Policy: 2003, D. Ravitch, ed., Brookings Institute Press, Washington D.C., 2003.

20. J. H. Stapleton, Linear Statistical Models, Wiley-Interscience, New York, 1995.

21. Ticket to Nowhere: The Gap Between Leaving High School and Entering College and High-Performance Jobs, in Thinking K-16, The Education Trust, Washington, D.C., 1999.

22. A. Venezia, M. W. Kirst, and A. Antonio, Betraying the College Dream: How Disconnected K-12 and Post-Secondary Education Systems Undermine Student Aspirations, Stanford Institute for Higher Education, Stanford, CA, 2003.

23. R. K. Walker, Student's Conceptions of Mathematics and the Transition from a Standards-Based Mathematics Education to College Mathematics, Ph.D. dissertation, Western Michigan University, 1999.

RICHARD O. HILL received a B.S. in mathematics from Trinity College, Hartford, and a Ph.D. in algebraic topology from Northwestern University under the direction of M. Mahowald. He has published papers in algebraic topology, numerical linear algebra, and mathematics education. He is a professor of mathematics at Michigan State University, where he has directed its Emerging Scholars Program since 1992. He is currently interested in transition issues in mathematics from high school to college and in the training of future high school mathematics teachers.

Mathematics Department, Michigan State University, East Lansing, MI 48824. USA.

hill@math.msu.edu.

THOMAS H. PARKER (B.S. Brown 1976, Ph.D. Stanford 1980) is a professor of mathematics at Michigan State University; he previously held positions at Harvard and Brandeis Universities. He has published numerous articles on geometric analysis and mathematical physics. He regularly teaches courses for preservice teachers and has written, with S. Baldridge, a textbook entitled Elementary Mathematics for Teachers (Sefton-Ash Publishers, 2004).

Mathematics Department, Michigan State University, East Lansing, MI 48824, USA.

parker@math.msu.edu. 